\title{
Simulations of terrestrial in-situ cosmogenic-nuclide production
}

\author{
R.C. Reedy ${ }^{a, *}$, K. Nishiizumi ${ }^{b, 1}$, D. Lal ${ }^{\text {c }}$, J.R. Arnold ${ }^{\text {b }}$, P.A.J. Englert ${ }^{\text {d }}$, J. Klein ${ }^{\text {e, }}$, \\ R. Middleton ${ }^{\mathrm{e}}$, A.J.T. Jull ${ }^{\mathrm{f}}$ and D.J. Donahue ${ }^{\mathrm{f}}$ \\ a Space Science and Technology Division, MS-D436, Los Alamos National Laboratory, Los Alamos, NM 87545, USA \\ 'Department of Chemistry, 0524, University of California, San Diego, La Jolla, CA 92093, USA \\ ' Scripps Institution of Oceanography, 0220, Unicersity of California, San Diego, La Jolla, CA 92093, USA \\ "Nuclear Science Facility, San Jose State Unitersity, San Jose, CA 95192, USA \\ 'Department of Physics, University of Pennsyllania, Philadelphia, PA 19104, USA \\ ${ }^{f}$ NSF Accelerator Facility for Radioisotope Analysis, Unimersity of Arizona, Tucson, AZ 85721, USA
}


NUCLEAR INSTRUMENTS AND METHODS IN PHYSICS RESEARCH

Editor-in-Chief: Kai Siegbahn

\section{SECTION B: BEAM INTERACTIONS WITH MATERIALS AND ATOMS}

Editors: H.H. Andersen \& L.E. Rehn

\author{
Editorial Board: \\ R.S. AVERBACK (Urbana) \\ K. BETHGE (Frankfurt) \\ G. FOTI (Catania) \\ F. FUJIMOTO (Osaka) \\ P.L.F. HEMMENT (Guildford) \\ K.S. JONES (Gainesville) \\ G.J.F. LEGGE (Melbourne)
}

\author{
W.N. LENNARD (Ontario) \\ F. PÁSZTI (Budapest) \\ S.T. PICRAUX (Albuquerque) \\ D.B. POKER (Oak Ridge) \\ J.P. RIVIERE (Poitiers) \\ B. STRITZKER (Augsburg) \\ M. SZYMOŃSKI (Cracow)
}

\author{
T. TOMBRELLO (Pasadena) \\ E. UGGERHØJ (Aarhus) \\ F. VAN DER VEEN (Amsterdam) \\ Zhong-Lie WANG (Beijing) \\ G. WEYER (Geneva) \\ A.E. WHITE (Murray Hill) \\ I. YAMADA (Kyoto)
}

\section{Information for Authors}

Section B of Nuclear Instruments and Methods in Physics Research (NIM B) has been formed to provide a special forum for the discussion of all aspects of the interaction of energetic beams with atoms, molecules and aggregate forms of matter. This includes ion beam analysis and ion beam modification of materials as well as studies of the basic interaction mechanisms of importance for this work. The Editors invite submiscion of both theoretical and experimental papers of original research in this area.

Contributions should be in English and should be submitted in duplicate directly to the Editors. Together with the hard copies an exactly identical electronic version on disketle can be submitted. To assist in minimizing publication time. il is suggested that manuscripts originating from Europe. India. The Middle East and Africa be sent to Prof. Andersen, and manuscripts from The Americas. The Far East (China and Japan) and Australasia to Dr. Rehn.

\section{Prof. H.H. Andersen}

The Niels Bohr Institute. Orsted Laboratory

Universitetsparken 5 .

DK-2100 Copenhagen $\emptyset$. Denmark

Tel + $4535320482 \quad$ FAX: +4535320460

e-mail: nimb@mcyer.fys.ku.dk

\section{Dr. L.E. Rehn}

Materials Science Division, Bldg 223, Rm S231

Argonne National Laboralory, 9700 South Cass Avenue

Argonne, IL 60439, USA

Tel. +17082529297 FAX +17082523308

e-mail: lynn_rehn@qmgate.anl.gov

Short contributions of less than 1500 words and not subdivided into sections may be published as Letters to the Editor in a shorter time than regular articles as the proofs will normally be corrected by the Publisher.

Correspondence with the Publisher regarding articles accepted for publication or the return of corrected preofs should be addressed to: NIM B Editors, Elsevier Science B.V. P. B. Box 103, 1000 AC Amsterdam. The Netherlands

FAX: +31205862775 telex: 10704 ESP OM tel. $+3120586250 \mathrm{Oj}$ e-mail: nimb-j@elsevier.nl

There are no page charges to individuals or institutions for publication of an article in this journal. 50 reprints of each article will be supplied free of charge. Further reprints can be ordered from the Publisher on the Order Form sent out with the proofs.

\section{Subscriptions}

Nuctear Insmuments and Mahods in Physics Rescarch - B (ISSN 0168-58.3X). For 1994, volumes 8.3-94 are scheduled for publication. Subscriplion prices are available upon request from the Publisher. A combined subscription to NIM A volumes 337-35I and NIM B volumes 8.94 is avaitable al a reduced rate.

Subscriptions are accepted on a prepaid basis only and are entered on a calendar year basis. Issues are sent by surface mail except to the following countries where air delivery via SAL is ensured: Argentina, Australia, Brazil, Canada, China, Hong Kong, India, Israel. Japan, Malaysia, Mexico, New Zealand, Pakistan, Singapore, South Africa, South Korea. Taiwan, Thailand, USA. For all other countries airmail rates are available upon request.

Please address all requests regarding orders and subscription queries to: Elsevier Science, Journal Department, P.O. Box 211 , 1000 AE Amsterdam. The Netherlands tel. +31205803642 , FAX: +31205803598 . Claims for issues not received should be made within six months of our publication (mailing) date.

\section{Information for Advertisers}

Advertising orders and enquiries can be sent to the Advertising Manager. Elsevier Science B.V., Advenising Department, P.O. Box 2ll, I000 AE Amsterdam. The Netherlands, tel. + 3120515 3220. FAX: + 3120683 3041. UK: T.G. Scott \& Son, Portland House. 21 Narhorough Rd, Cosby, Leicestershire LE9 5TA tel. +44533753 333; fax: + 44533750 522, attn. Tim Blake. USA, Canada: Weston Media Associates, Daniel S. I ipner, P.O. Box 1110, Greens Farms, CT 06436-1110, USA, tel. + I 203261 250). FAX: + 12032610101

Elsevier Science B.V.: All rights reserved. No part of this publication may be reproduced, stored in a tetrieval syctem or transmitted in any form or by any means, electronic, mechanical. photocopying, recording or otherwise, without the written permission of the Putlisher, Elsevier Science B.V. Copyright \& Permissions Dept.. P.O. Box 521, 1000 AM Amsterdam, The Netherlands.

Special rezulations for author - Upon acceptance of an article by the journal, the Author(s) will be asked to Iransfer copyright of the article to the Publisher. This transfer will ensure the widest possible discemination of information.

Special regulations for reaters in the USA - This journal has been registered with the Copyright Clearance Center, Inc. Consent is given for copying articles for personal or internal use, or for the personal use of specific clients. This consent is given on the condition that the copier pays through the Center the per copy fee stated on the first page of each article for copying beyond that permilted by Sections 107 or 108 of 1 he US Copyright Law. The appropriate fee should be forwarded with a copy of the first page of the article to the Copyrighi Clearance Center, Inc., 27 Congress St.. Salem, MA 01970. USA. If no code appears on an article, the Author has not given consent to copy and permission to copy must be oblained directly from the Author. The fee indicated on the first page of an article in this issue will apply retroactively to all articles published in the journal, regardless of the year of publication. This consent does not extend to other kinds of copying, such as for general distribution, resale, advertising and promotion purposes. or for creating new collective works. Special written permission must be obtained from the publisher for such copying.

US mailing notice - Nuclear Instruments and Methods in Physics Research - B (ISSN 0168-583X) is published monthly (for eight months of the year) and three times a month from March to June by Elsevier Science. Molenwerf 1, P.O. Box 211. IOX0 AE Anisterdam. The Netherlands. Annual subscription price in the USA is US $\$ 4352$ (US $\$$ price valid in North, Central and South America only), including air speed delivery. Second class postage paid at Jamaica NY 11431

USA POSTMASTERS: Send address changes to Nuclear Instruments and Methods in Physics Research - B, Publications Expediting. Inc.. 200 Meacham Avenue, EImont NY 11003 . Airfreight and mailing in the USA by Publications Expediting.

No responsibility is assumed by the Publisher for any injury and/or damage to persons or properly as a matter of products liability, negligence or otherwise, or from any use or operation of any methods, products, instruclions or ideas contained in the materials herein. Although all advertising material is expected to conform to ethical standards, inclusion in this publication does not constitute a guarantee or endorsement of the quality or value of such product or of the claims made of it by its manufacturer.

Published monthly 


\title{
Simulations of terrestrial in-situ cosmogenic-nuclide production
}

\author{
R.C. Reedy ${ }^{a}, *$, K. Nishiizumi ${ }^{b, 1}$, D. Lal ${ }^{c}$, J.R. Arnold ${ }^{\text {h }}$, P.A.J. Englert ${ }^{d}$, J. Klein ${ }^{\text {e }}$, \\ R. Middleton ${ }^{\mathrm{c}}$, A.J.T. Jull ${ }^{\mathrm{f}}$ and D.J. Donahue ${ }^{\mathrm{f}}$ \\ ${ }^{a}$ Space Science and Technology Division, MS-D436, Los Alamos National Laboratory, Los Alamos, NM 87545, USA \\ 'Department of Chemistry, 0524, Unitersity of Califomia, San Diego, La Jolla, CA 92093, USA \\ 'Scripps Instifution of Oceanography, 0220, University of California, San Diego, La Jolla, CA 92093, USA \\ "Nuclear Science Facility, San Jose State University, San Jose, CA 95192, USA \\ 'Department of Physics, University of Pennsyluania, Philadelphia, PA 19104, USA \\ ${ }^{\prime}$ NSF Accelerator Facility for Radioisotope Analysis, Unicersity of Arizona, Tucson, AZ 8572I, USA
}

\begin{abstract}
Targets of silicon and silicon dioxide were irradiated with spallation neutrons to simulate the production of long-lived radionuclides in the surface of the Earth. Gamma-ray spectroscopy was used to measure ${ }^{7} \mathrm{Be}$ and ${ }^{22} \mathrm{Na}$, and accelerator mass spectrometry was used to measure ${ }^{10} \mathrm{Be},{ }^{14} \mathrm{C}$, and ${ }^{26} \mathrm{Al}$. The measured ratios of these nuclides are compared with calculated ratios and with ratios from other simulations and agree well with ratios inferred from terrestrial samples.
\end{abstract}

\section{Introduction}

The interactions of galactic-cosmic-ray particles in the Earth's atmosphere produce a cascade of particles, some of which reach the Earth's surface and produce cosmogenic nuclides. Neutrons are the dominant producer of nuclides in the top meter of the Earth's surface, and muons become a major source of cosmogenic nuclides below a few meters. Long-lived cosmogenic radionuclides, such as 5730 -year ${ }^{14} \mathrm{C}, 0.3-\mathrm{Ma}{ }^{36} \mathrm{Cl}$, $0.7-\mathrm{Ma}{ }^{26} \mathrm{Al}$, and $1.5-\mathrm{Ma}{ }^{\mathrm{I} 0} \mathrm{Bc}$, and a few rare stable nuclides, such as ${ }^{3} \mathrm{He}$ and ${ }^{21} \mathrm{Ne}$, made in-situ in certain materials can be used to study recent exposure histories [1]. The advances in the analyses of long-lived radionuclides using accelerator mass spectrometry (AMS) have revolutionized the use of these radionuclides, especially for in-situ terrestrial applications. At present, the use of these cosmogenic nuclides to study histories of targets or of cosmic radiation is often limited by inadequately known production rates.

Some production rates and ratios have been inferred from measurements of terrestrial samples with known irradiation conditions (e.g., refs. [2-6]). There are some uncertainties in the exposure ages and irradiation conditions of these samples, and only a few radionuclides (e.g., ${ }^{10} \mathrm{Be}$ and ${ }^{26} \mathrm{Al}$ ) have been measured. A wide range of production rates have also been

* Corresponding author. Tel. +1 5056675446 , fax +1505 665 4414, e-mail rreedy@lanl.gov.

1 Present address: Space Sciences Laboratory, University of California, Berkeley, CA 94720, USA. theoretical inferred (e.g., refs. [7,8]). These and other calculations (e.g., refs. $[9,10]$ ) for production of these nuclides by nucleons and muons could be improved with laboratory measurements of production cross sections and relative production ratios.

Laboratory simulations of these processes have many limitations, such as not reproducing the complex mix of particles and their energies, but do provide a controlled irradiation of well-characterized samples. A scries of irradiations at the Los Alamos Clinton P. Anderson Meson Physics Facility (LAMPF) have simulated the production of long-lived radionuclides in surface rocks. Here we report on synthetic quartz and silicon that were exposed to neutrons. Preliminary results with some details not presented here were reported earlier [11-13]. Irradiations with muons were also done $[11,12]$ and will be reported separately.

\section{Experimental}

To simulate the production rates and ratios duc to the nucleon component (primarily neutrons) of cosmic rays, an irradiation was conducted using spallation neutrons produced in the beam stop of the $\sim 1-\mathrm{mA}$ $800-\mathrm{MeV}$ proton beam at LAMPF. The beam stop produces a large flux of secondary particles, espccially neutrons. Most charged secondary particles are stopped by ionization energy losses near the beam stop. Neutrons travel until they undergo nuclear interactions. Samples were exposed to these particles in the Los Alamos Spallation Radiation Effects Facility 
Table 1

Measured radionuclide concentrations $\left(10^{10}\right.$ atoms $\left./ \mathrm{g}\right)$ in irradiations with spallation neutrons near the LAMPF beam stop (numbers in parentheses are the uncertainties of the last digits of the measurement)

\begin{tabular}{lllllrr}
\hline Target & ${ }^{7} \mathrm{Be}$ & ${ }^{10} \mathrm{Be}$ & ${ }^{14} \mathrm{C}$ & ${ }^{22} \mathrm{Na}$ & ${ }^{2 \hbar} \mathrm{Al}$ & ${ }^{\mathrm{a}} \mathrm{Al}^{\mathrm{b}}$ \\
\hline $\mathrm{Si}$ & $40.1(0.4)$ & $7.69(0.46)$ & $19.2(4)$ & $553(5)$ & $1320(90)$ & $1410(110)$ \\
$\mathrm{SiO}_{2}$ & $162(1)$ & $93.0(4.7)$ & $303(3)$ & $256(5)$ & $722(50)$ & $660(52)$ \\
$\mathrm{O}^{\mathrm{c}}$ & $269(2)$ & $168(9)$ & $552(6)$ & - & - & - \\
\hline
\end{tabular}

${ }^{a}$ Measured in that sample only.

b From averages based on measurements of both Si-containing samples.

' Oxygen, as inferred from the $\mathrm{SiO}_{2}$ and $\mathrm{Si}$ measurements.

(LASREF) around the beam stop. The particle distributions at various locations in LASREF have becn characterized $[14,15]$ and are roughly similar to those in the Earth's surface. Targets of silicon, $\mathrm{SiO}_{2}$, and several monitor foils were irradiated for about a day with these spallation neutrons.

The activities in the monitor foils and of the shortlived radionuclides, such as $2.6-\mathrm{a}{ }^{22} \mathrm{Na}$ and $53-\mathrm{d}{ }^{7} \mathrm{Be}$, produced in the silicon and $\mathrm{SiO}_{2}$ were determined by non-destructive high-resolution gamma-ray spectrometers at Los Alamos. At LAMPF, picces of the silicon and $\mathrm{SiO}_{2}$ were dissolved along with $\mathrm{Al}$ and $\mathrm{Be}$ carriers. The $\mathrm{Al}$ and $\mathrm{Bc}$ were separated and taken to San Diego, where they were further purified $[16,17]$. The ${ }^{26} \mathrm{Al} /{ }^{27} \mathrm{Al}$ and ${ }^{10} \mathrm{Be} /{ }^{9} \mathrm{Be}$ ratios were measured on the University of Pennsylvania's tandem Van de Graaff accelerator $[18,19]$. The measured concentrations of these radionuclides are given in Table 1 .

Measurements of ${ }^{14} \mathrm{C}$ were separately made for these beam-stop samples. Two different extractions were performed at Tucson on samples of a few $\mathrm{mg}$ of $\mathrm{Si}$ and $\mathrm{SiO}_{2}$ and also on samples that had been physically diluted with quartz powder. Samples were precombusted to remove any organic contamination and then heated to melting [20]. Any $\mathrm{CO}$ was converted to $\mathrm{CO}_{2}$. The $\mathrm{CO}_{2}$ was measured volumetrically and reduced to graphite. The graphite was analyzed along with standards by AMS at the University of Arizona NSF Accelerator Facility for Radioisotope Analysis as described in ref. [21]. The results for the two different extractions agreed very well [13], and only the averages are given in Table 1.

\section{Results}

The concentrations of the radionuclides (Table 1) were high and easily measured. The production of ${ }^{7} \mathrm{Be}$, ${ }^{10} \mathrm{Be}$, and ${ }^{14} \mathrm{C}$ from pure oxygen in Table 1 was determined from the $\mathrm{Si}$ and $\mathrm{SiO}_{2}$ measurements. The ${ }^{22} \mathrm{Na}$ in the $\mathrm{SiO}_{2}$, which is made only from the silicon, is in good agreement (1\%) with the ${ }^{22} \mathrm{Na}$ measurement in $\mathrm{Si}$. However, the ${ }^{26} \mathrm{Al}$ measurements in $\mathrm{Si}\left(132 \times 10^{11}\right.$ atoms $/ \mathrm{g}$ ) and in the $\mathrm{SiO}_{2}$ corrected to pure $\mathrm{Si}(154 \times$ $10^{11}$ atoms $/ g$ ) disagree by $17 \%$, which is slightly greater than the sum of the $\approx 7 \%$ errors for each measurement. Below, we use the average of these values, $141 \times 10^{11}$ atoms $/ g$ for pure Si and $66 \times 10^{11}$ atoms $/ g$ for $\mathrm{SiO}_{2}$.

The ${ }^{7} \mathrm{Be} /{ }^{10} \mathrm{Be}$ ratio in the $\mathrm{Si}$ is 5.2 , which is less than the ratio of $\approx 7.7(5.39 \mathrm{mb} / \approx 0.7 \mathrm{mb})$ measured in $\mathrm{Si}$ irradiated with $600-\mathrm{MeV}$ protons $[22,23]$. The ${ }^{7} \mathrm{Be} /{ }^{10} \mathrm{Be}$ production ratio in oxygen is 1.6 , which is much less than the proton-induced ratios in oxygen of 8.9 and 5.4 at 135 and $550 \mathrm{MeV}$, respectively (from ref. [24], using revised half-lives), and of 171 and 15.7 at 49 and $91 \mathrm{MeV}$, respectively [25]. As evident from the above ${ }^{7} \mathrm{Be} /{ }^{10} \mathrm{Be}$ ratios and as previously noted for ${ }^{10} \mathrm{Be}$ [26], neutrons and protons produce these two nuclides in relatively different yields and cross sections.

These results yield ${ }^{26} \mathrm{Al} /{ }^{10} \mathrm{Be}$ ratios of 183 in $\mathrm{Si}$ and 7.1 in $\mathrm{SiO}_{2}$. The ${ }^{10} \mathrm{Be}$ and ${ }^{26} \mathrm{Al}$ contents of quartz from glacially-polished rock exposed to cosmic rays for $\approx 11$ $\mathrm{ka}$ gave an ${ }^{26} \mathrm{Al} /{ }^{10} \mathrm{Be}$ ratio of $6.0 \pm 0.4$ [4]. Other measurements for natural samples gave similar production ratios, see Table 2 . These ${ }^{26} \mathrm{Al} /{ }^{10} \mathrm{Be}$ production ratios agree well with our ratio of $7.1 \pm 0.7$ from spallation neutrons reacting with $\mathrm{SiO}_{2}$.

The ${ }^{10} \mathrm{Be} /{ }^{7} \mathrm{Be}$ and ${ }^{26} \mathrm{Al} /{ }^{10} \mathrm{Be}$ ratios that we obtained from our irradiations can also be compared with preliminary results $[11,12]$ from the irradiation of $\mathrm{SiO}_{2}$

Table 2

${ }^{26} \mathrm{Al} /{ }^{10} \mathrm{Be}$ ratios measured from these simulations or some terrestrial samples and several calculated ratios

\begin{tabular}{|c|c|c|}
\hline Sample(s) & $\begin{array}{l}\text { Measured } \\
\text { ratio(s) }\end{array}$ & $\begin{array}{l}\text { Calculated } \\
\text { production ratio }\end{array}$ \\
\hline$\overline{\text { Early predictions }}$ & & $4.2[8]-20.7[7]$ \\
\hline Libyan desert glass & $\leq 7$ & \\
\hline In-situ quartz & $2.5-6.7 \quad[3]$ & $\Rightarrow \approx 6$ \\
\hline Sierra quartz & $6.0 \pm 0.4$ & $\approx 8^{\mathrm{a}}$ \\
\hline Antarctic rocks & $\sim 6.2$ & $\approx 8^{\mathrm{a}}$ \\
\hline Antarctic rocks & $6.5 \pm 1.3$ & $\approx 8$ \\
\hline LAMPF, neutrons & $7.1 \pm 0.7^{a}$ & $\approx 8^{\mathrm{a}}$ \\
\hline
\end{tabular}

a This work. 
with stopping negative muons $\left(\mu^{-}\right)$. The ${ }^{10} \mathrm{Bc} /{ }^{7} \mathrm{Bc}$ ratios vary widely (e.g., $\sim 23$ for the stopped $\mu^{-}$), even greater than the variations noted above for cross-section ratios at various proton energies. $T$ he ${ }^{26} \mathrm{Al} /{ }^{10} \mathrm{Be}$ ratios for stopped muons $(\approx 7.0)$ and neutrons arc similar.

Our ratios for ${ }^{14} \mathrm{C} /{ }^{10} \mathrm{Be}$ in $\mathrm{Si}, \mathrm{SiO}_{2}$, and oxygen are $2.50,3.26$, and 3.29 , respectively. Using the proton cross sections of refs. [22,23,25] for ${ }^{10} \mathrm{Be}$ and of ref. [27] for ${ }^{14} \mathrm{C}$, we can compare our ratios for neutrons with proton-induced ratios. These ratios for protons reacting with $\mathrm{Si}$ and $\mathrm{O}$ increase with decreasing proton energy, with ratios near unity for $\sim 500 \mathrm{MeV}$ and $\sim 10$ for $\sim 50-70 \mathrm{MeV}$ protons, but scatter about our measured ratios.

Using the cross sections for ${ }^{10} \mathrm{Be}$ and ${ }^{26} \mathrm{Al}$ from ref. [26] and ref. [10], respectively, ${ }^{26} \mathrm{Al} /{ }^{10} \mathrm{Be}$ ratios were calculated for both the LAMPF irradiations and for natural irradiations. Although the exact spectral shapes for the energetic particles in these irradiations are not well known, we can get some ideas of relative trends and whether the cross sections are reasonably consistent with the measurements. Our calculated ${ }^{26} \mathrm{Al} /{ }^{10} \mathrm{Be}$ ratios in Table 2 are in good agreement with the ratios from our simulation and for natural quartz. Using the cross sections for ${ }^{22} \mathrm{Na}$ from $\mathrm{Si}$ in ref. [9], we calculated $a^{26} \mathrm{Al} /{ }^{22} \mathrm{Na}$ ratio similar to the measured ratio. Our results and the cross sections for ${ }^{10} \mathrm{Be}$ production in ref. [26] suggest that the neutron-induced cross sections for ${ }^{7} \mathrm{Be}$ from oxygen are $\sim 0.7$ of those measured for protons. For ${ }^{14} \mathrm{C}$, we found that we needed to increase the assumed cross sections of ref. [9] for production of ${ }^{14} \mathrm{C}$ from oxygen by $10 \%$ and more at the lowest energies to get better agreement with the measured ratio.

Our cross sections for ${ }^{10} \mathrm{Be},{ }^{14} \mathrm{C}$, and ${ }^{26} \mathrm{Al}$ gave good agreement between calculated production rates and activities measured in the Knyahinya meteorite [28]. To get production rates for terrestrial samples, we plan to use the Monte Carlo particle transport/production codes used by ref. [28] and our cross sections.

\section{Conclusions}

Spallation neutrons near the LAMPF beam stop were used to study the production of ${ }^{7} \mathrm{Be},{ }^{10} \mathrm{Be},{ }^{14} \mathrm{C}$, ${ }^{22} \mathrm{Na}$, and ${ }^{26} \mathrm{Al}$ in silicon and $\mathrm{SiO}_{2}$. These irradiations gave ${ }^{26} \mathrm{Al} /{ }^{10} \mathrm{Be}$ ratios similar to those measured with documented natural samples, indicating that other ratios from our irradiations could be applied to natural samples. Production ratios varied with the target and with the energy and the nature of the incident particles, illustrating the complex nature of predicting such nuclear interactions and their ratios.

Several excitation functions for the production of these radionuclides were tested. Some sets of cross sections $\left({ }^{10} \mathrm{Be},{ }^{22} \mathrm{Na}\right.$, and $\left.{ }^{26} \mathrm{Al}\right)$ were found to be good. Other cross-section sets for production by neutrons had to be modified $\left({ }^{14} \mathrm{C}\right)$ or were shown to be poor $\left({ }^{7} \mathrm{Be}\right)$. These good or modified cross sections are being used for calculations of cosmogenic-nuclide production rates in extraterrestrial materials and could be used for terrestrial applications.

Whilc simulations at accelerators, such as those reported here, have limitations, thcy are useful in determining and checking relative production rates in terrestrial samples. The controlled nature of such irradiations is an advantage for many problems, such as determining production from elements that are hard to study directly in natural samples, such as sodium. They also can give production ratios for radioactive nuclides relative to stable nuclides, e.g. ${ }^{26} \mathrm{Al} /{ }^{21} \mathrm{Ne}$.

\section{Acknowledgements}

We thank D. Davidson for her assistance in the irradiations at the beam stop and G. Butler and the staff of the INC counting room for providing the facilities and spectral-unfolding codes for the gamma-ray spectroscopy. This work was mainly supported by NASA, NSF, the German Science Foundation (DFG), and by the Institute of Geophysics and Planetary Physics at Los Alamos. The work at Los Alamos was done under the auspices of the U.S. Department of Energy.

\section{References}

[1] D. LaI, Annu. Rev. Earth Planet. Sci. 16 (1988) 355.

[2] J. Klein, R. Giegengack, R. Middleton, P. Sharma, J.R. Underwood Jr. and R.A. Weeks, Radiocarbon 28 (1986) 547.

[3] K. Nishiizumi, D. Lal, J. Klein, R. Middleton and J.R. Arnold, Nature 319 (1986) 134.

[4] K. Nishiizumi, E.L. Winterer, C.P. Kohl, J. Klein, R. Middleton, D. Lal and J.R. Arnold, J. Geophys. Res. 94 (1989) $17,907$.

[5] K. Nishiizumi, C.P. Kohl, J.R. Arnold, J. Klein, D. Fink, and R. Middleton, Earth Planet. Sci. Lett. 104 (1991) 440.

[6] E.T. Brown, J.M. Edmond, G.M. Raisbeck, F. Yiou, M.D. Kurz and E.J. Brook, Geochim. Cosmochim. Acta 55 (1991) 2269

[7] Y. Yokoyama, J. Reyss and F. Guichard, Earth Planet. Sci. Lett. 36 (1977) 44.

[8] D. Lal and J.R. Arnold, Proc. Indian Acad. Sci. (Earth Planet. Sci.) 94 (1985) 1.

[9] R.C. Reedy and J.R. Arnold, J. Geophys. Res. 77 (1972) 537. 
[10] R.C. Reedy, Nucl. Instr. and Meth. B 29 (1987) 251.

[11] R.C. Reedy, D. Lal, M. Laffoon, K. Nishiizumi, J.R. Arnold, D. Elmore, P. Kubik, J. Klein, R. Middleton and P. Englert, Progress at LAMPF 1987 (Los Alamos National Laboratory report LA-11339-PR, 1988) p. 148.

[12] J. Klein, K. Nishiizumi, R.C. Reedy, P. Englert and R. Middleton, Lunar and Planetary Science XIX (Lunar and Planetary Institute, Houston, 1988) p. 609.

[13] A.J.T. Jull, P.A.J. Englert, D.J. Donahue, R.C. Reedy and D. Lal, Lunar and Planetary Science XX (Lunar and Planetary Institute, Houston, 1989) p. 490.

[14] D.R. Davidson, R.C. Reedy, L.R. Greenwood, W.F. Sommer and M.S. Wechsler, Proc., Influence of Radiation on Material Properties, 13th, 1986, Seattle (Am. Soc. Testing Materials, Philadelphia, 1987) p. 730.

[15] D.R. Davidson, thesis, Iowa State Univ. (1990) $162 \mathrm{pp.}$

[16] K. Nishiizumi, D. Elmore, X.Z. Ma and J.R. Arnold, Earth Planet. Sci. Lett. 70 (1984) 157.

[17] K. Nishiizumi, J. Klein, R. Middleton and J.R. Arnold, Earth Planet. Sci. Lett. 70 (1984) 164.

[18] J. Klein, R. Middleton and H. Tang, Nucl. Instr. and Meth. 193 (1982) 601.

[19] R. Middleton, J. Klein, G.M. Raisbeck and F. Yiou, Nucl. Instr. and Meth. 218 (1983) 430.

[20] A.J.T. Jull, D.J. Donahue and T.W. Linick, Geochim. Cosmochim. Acta 53 (1989) 1295.

[21] T.W. Linick, A.J.T. Jull, L.J. Toolin and D.J. Donahue, Radiocarbon 28 (1986) 522.
[22] R. Michel, B. Dittrich, U. Herpers, F. Peiffer, T. Schiffmann, P. Cloth, P. Dragovitsch and D. Filges, Analyst 114 (1989) 287.

[23] B. Dittrich, U. Herpers, H.J. Hofmann, W. Wölfli, R. Bodemann, M. Lüpke, R. Michel, P. Dragovitsch and D. Filges, Nucl. Instr. and Meth. B 52 (1990) 588.

[24] B.S. Amin, S. Biswas, D. Lal and B.L.K. Somayajulu, Nucl. Phys. A 195 (1972) 311.

[25] R. Bodemann, H.-J. Lange, I. Leya, R. Michel, T. Schiekel, R. Rösel, U. Herpers, H.J. Hofmann, B. Dittrich, M. Suter, W. Wölfli, B. Holmqvist, H. Condè and P. Malmborg, Nucl. Instr. and Meth. B 82 (1993) 9.

[26] C. Tuniz, C.M. Smith, R.K. Moniot, T.H. Kruse, W. Savin, D.K. Pal, G.F. Herzog and R.C. Reedy, Geochim. Cosmochim. Acta 48 (1984) 1867.

[27] J.M. Sisterson, A.J.T. Jull, A. Beverding, A.M. Koehler, C. Castaneda, J. Vincent, D.J. Donahue, P.A.J. Englert, C. Gans, J. Young and R.C. Reedy, these Proceedings (6th Int. Conf. on Accelerator Mass Spectrometry (AMS6), Canberra-Sydney, Australia, 1993) Nucl. Instr. and Meth. B 92 (1994) 510.

[28] R.C. Reedy, J. Masarik, K. Nishiizumi, J.R. Arnold, R.C. Finkel, M.W. Caffee, J. Southon, A.J.T. Jull and D.J. Donahue, Lunar and Planetary Science XXIV (Lunar and Planetary Institute, Houston, 1993) p. 1195. 


\section{INSTRUCTIONS TO AUTHORS}

Contributions to Secrion $R$ of Nuclear Instruments and Methods in Physics Research must be in English and should have an abstract. The manuscript and copies of figures should be submitted in duplicate, together with one set of good quality figure material (for production of the printed figures), to one of the Editors, Prof. H.H. Andersen or Dr. L.E. Rehn. Together with the manuscript an exactly identical electronic version on diskette can be submitted. Upon acceptance of the article for publication, both the manuscript and the diskette will be sent by the Editor to the Publisher. It is suggested that manuscripts originating from Europe, India, The Middle East and Africa be sent to Copenhagen and manuscripts from The Americas, The Far East and Australasia, to Argonne.

Prof. H.H. Andersen

The Niels Bohr Institute, $\varnothing$ rsted Laboratory

Universitetsparken 5, DK-2100 Copenhagen $\varnothing$

Denmark

Tel. +4535320482 FAX: +4535320460

e-mail:nimb@meyer.fys.ku.dk
Dr. L.E. Rehn

Materials Science Division, Bldg. 223, RM S231

Argonne National Laboratory, 9700 South Cass Ave Argonne IL 60439, USA

Tel. +17082529297 FAX: + 17082523308

e-mail: lynn_rehn@qmgate.anl.gov

Short contributions of less than 1500 words and not subdivided into sections may be published as Letters to the Editor in a shorter time than regular articles as the proofs will normally be corrected by the Publisher.

\section{Preparation of manuscripts}

Manuscripts should be typed throughout with double line spacing and wide margins on numbered pages.

The title page(s) should contain, in addition to the article title, author(s) names and affiliations, the text of related footnotes and the text of the abstract.

Tables should be typed on separate sheets at the end of the manuscript. In addition to its serial number, each table should have a sufficiently detailed heading or caption to explain the data displayed in it.

Figures should be numbered and their captions listed together at the end of the manuscript.

References in the text to other publications should be numbered consecutively within square brackets, for example:

"Using a similar technique [1]..." or "As outlined in ref. [2],..." and listed together at the end of the text, for example:

[1] G.A. Smith, K.-H. Park, G.-C. Wang, T.-M. Lu and W.M. Gibson, Surf. Sci. 233 (1990) 115.

[2] T.Y. Tan, in: Defects in Semiconductors, eds. J. Narayan and T.Y. Tan (North-Holland, Amsterdam, 1981) p. 163.

[3] H. Yamazaki. Proc. 6th Int. Conf. on Ion Beam Modification of Materials, Nucl. Instr. and Meth. B 39 (1989) 433.

In the case of multiple authorship all authors should be listed in the references provided they number less than ten. Only in case of more than ten authors is the first author et al. acceptable.

Formulae in the manuscript should be clearly written or typed with particular consideration given to characters that may be misinterpreted,

$$
\begin{array}{cll}
\text { c.g. o (lower case) O (cap.) } 0 \text { (zero) }{ }^{\circ}(\mathrm{deg}) & \mathrm{I} \text { (cap) } \mid \text { (el) } 1 \text { (one) ' (prime) } & \text { c, C; p, P; s, S; etc. } \\
\times \text { (times) } \times \text { (lower case) X (cap.) } & \Sigma \text { (sigma) } \perp \text { (sum). } & \text { k, K. k (kappa) }
\end{array}
$$

If necessary, unusual symbols should be explained in pencil in the margin.

\section{Preparation of figures}

The Publisher requires a set of good quality drawings and photographs to produce the printed line figures and halftone plates in the journal. Photographic copies ("glossy prints") of drawings are also acceptable for the line figures if they have been sharply focused and evenly exposed.

Line figures: The drawings or glossy prints supplied for the line figures should be 1.5-3 times larger than the printed size of the figures and should contain all the required lettering.

Figures are preferably reduced to a single column width $(7.6 \mathrm{~cm})$ unless their complexity, large width-to-height ratio, or need to display special detail makes a larger format necessary (max. printed width $\approx 20 \mathrm{~cm}$ ). Inappropriately sized lettering on a figure may prevent its reduction to the size optimum for its information content. The lettering used on a drawing should be chosen so that after reduction, the height of numbers and (capital) letters falls within the range 1.2-2.4 $\mathrm{mm}$. Care should be exercised in choosing the pen width of machine-plotted graphs. Frequently lines in these figures are too fine compared to the area of the figure.

Shaded areas in line figures should be shown by means of cross-hatching (or a matrix of dots) rather than a continuous grey "wash". Cross-hatching, after reduction, of density less than 25 lines/cm is satisfactory.

Half-tone plates: The photographs supplied for reproduction should he unmounted unless they form part of a composite figure and they should have a somewhat greater contrast than is desired in the printed figure. It is important that the photographs supplied are not already screened (overprinted with the point-matrix used by printers) or moiré patterns will form when they are screened for a second time. When necessary, the top side of a photograph should be marked. A reduction factor should be recommended for a photo when it is not obvious what detail in the photo is of interest.

Colour plates: Illustrations can be printed in colour when they are judged by the Editor to be essential to the presentation. The Publisher and the Author will each bear part of the extra costs involved. Further information concerning colour illustrations and the cost to the Author is available from the Publisher, or can be found in the first issue of volume 84 , p. 125. 


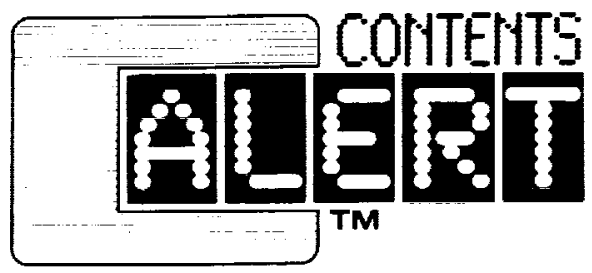

A CURRENT AWARENESS SEAVICE

FREE OF CHARGE

\section{FOR SCIENTISTS WORKING IN THE FIELD OF SURFACES, INTERFACES AND THIN FILMS \\ FOR SCIENTISTS WORKING IN THE FIELD OF MATHEMATICAL \& THEORETICAL METHODS IN PHYSICS}

As the number of scientific publications grows daily it becomes increasingly important to trace the most interesting publications in a way that costs as little time as possible.

Elsevier Science Publishers now provides CONTENTS-Alert, a free electronic service that can assist you in carrying out time-saving searches on a regular, two-weekly basis.

CONTENTS-Alert is a current awareness service which delivers, through e-mail, the tables of contents of a selected group of journals. Not only will you receive these tables of contents before or upon publication of the journals but you can also browse through these tables of contents at your own terminal, in your own time. A survey carried out among researchers using CONTENTS-Alert has shown that this free service is very convenient and time-effective.

We offer two versions of CONTENTS-Alert each covering a specific field. One version of CONTENTS-Alert includes journals on Surfaces, Interfaces and Thin Films, and one includes journals on Mathematical and Theoretical Methods in Physics.

Journals covering the field of Surfaces. Interfaces and Thin Fiims

Applied Surface Science

Chemical Physics Letters

Materials Science and Engineering: R: Reports

Nuclear Instruments and Methods in Physics Research: Section B

Surface Science (including Surface Science Letters)

Surface Science Reports

Thin Solid Films

Vacuum

Our e-mail for this version is:

RFC-822: C-ALERT@ELSEVIER.NL

$X .400: C=N L ; A=400 N E T ; P=S U R F ; O=E L S E V I E R ; S=C$-ALERT
Journals covering the field of Mathematical and

Theoretical Methods in Physics

Computer Physics Communications

Journal of Geometry and Physics

Nuclear Physics B

Physica A

Physica D

Physics Letters A

Physics Letters B

Physics Reports

Wave Motion

Our e-mail for this version is:

RFC-822: C-ALERT.MATHPHYS@ELSEVIER.NL

$X .400: C=N L ; A=400 N E T ; P=S U R F ; O=E L S E V I E R ;$

$$
S=\text { MATHPHYS; } G=C \text { - ALERT }
$$

Subscribe now to this tree pre-publication service and find out how useful CONTENTS-Alert really is. Just send your full address to the e-mail number quoted above that corresponds with the CONTENTS-Alert version you wish to receive, or send it by post and we will make sure you will receive CONTENTS-Alert every two weeks.

Please allow three weeks processing time for your free subscription.

Yes, please add my name to the circulation list of

\section{CONTENTS-Alert.}

Version: $\square$ Surfaces, Interfaces and Thin Films - Mathematical and Theoretical Methods in Physics

Return to:

ELSEVIER SCIENCE PUBLISHERS B.V.,

Att: Mr. M. Stavenga,

P.O. BOX 103, 1000 AC Amsterdam, The Netherlands

Fax 31205862580

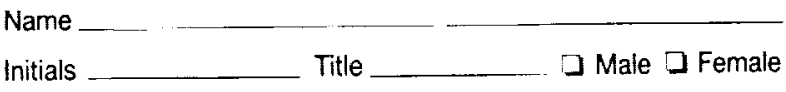

Institute

Department

Street/ PO Box

City

Country

Tel: Fax

E-mail 